\title{
Effect of Edge Geometry on Cutting Forces in Face Milling with Different Feed Rates
}

\author{
János Kundrák ${ }^{1}$, Angelos P. Markopoulos ${ }^{2}$, Tamás Makkai ${ }^{1}$, Nikolaos E. Karkalos ${ }^{2}$ \\ ${ }^{1}$ Institute of Manufacturing Science, University of Miskolc, Egyetemváros H-3515 Miskolc, Hungary. E-mail: kun- \\ drak@uni-miskolc.hu, tamas.makkai@uni-miskolc.hu \\ ${ }^{2}$ Laboratory of Manufacturing Technology, School of Mechanical Engineering, National Technical University of Athens, \\ Heroon Polytechniou 9, 15780 Athens, Greece. E-mail: amark@mail.ntua.gr,nkark@mail.ntua.gr
}

The fundamental goals of face milling such as high surface quality, dimensional accuracy and productivity can be attained by proper regulation of process parameters, mainly feed rate, depth of cut and cutting speed, but also by taking into consideration the particularities of workpiece material and by selecting the cutting insert with the appropriate geometrical characteristics such as angle $\kappa_{\mathrm{r}}$, rake angle and nose radius. In the present study, the focus is set on the comparison of three different commonly used milling insert types, namely rectangular, round and square regarding cutting forces under various process conditions, with a view to quantitatively evaluate their performance regarding cutting forces and specific cutting forces during face milling of steel workpieces and eventually determine which insert type leads to lower power demand for the same material removed volume. The findings of the present study indicate that the most favorable insert type is the rectangular one, followed by the square and the round one.

Keywords: Face milling, Cutting forces, Specific cutting forces, Milling insert type, Feed rate

\section{Introduction}

Milling is one of the most established machining processes, employed regularly in many high end industries, such as the automotive or the aerospace ones due to its versatility and efficiency, especially for the processing of prismatic components [1,2]. As there exist some conflicting goals regarding face milling such as productivity, surface quality and integrity, machining time and cost, the determination of suitable process parameters can be conducted through optimization techniques [3-5].

In general, as face milling has been employed since many decades, a considerable amount of experimental, theoretical and numerical studies has been conducted in this scientific field, as can be attested by a review of the relevant literature. As a consequence of these works, the effect of the basic process parameters such as feed rate $\left(v_{f}\right)$, depth of cut $\left(a_{p}\right)$, cutting speed $\left(v_{c}\right)$ on the outcome of the face milling process has been extensively studied for a variety of cutting tools, workpiece materials and milling strategies. Feed rate was identified as the predominant factor which affects cutting forces, as increased feed rate values increase considerably all cutting force components [6]. Furthermore, it was found that the increase of depth of cut leads also to an increase of cutting force due to the increase of tool-workpiece contact length and uncut chip cross-sectional area, whereas cutting speed has usually lower significance than the other two aforementioned parameters and its increase leads to a decrease of cutting forces due to higher temperatures causing softening of the workpiece material [7]. Moreover, there exist some other important parameters for industrial practice, which affect the face milling process and involve the combined effect of more than one process parameter. For example, the chip cross section area $A_{c}$, defined as the product of depth of cut and feed per tooth $\left(f_{z}\right)$ and the chip size ratio defined as the ratio $a_{p} / f_{z}$ are also crucial parameters in face milling [7, 8]. The latter regulates the region of chip deformation occurrence, with cases with $a_{p} / f_{z}$ lower than 1 indicating chip deformation perpendicular to the edge on the face of the cutting insert and cases with $a_{\mathrm{p}} / \mathrm{f}_{\mathrm{z}}$ higher than 1 indicating chip deformation perpendicular to the edge on the outer surface of the cutting insert [6]. It is interesting to note that recently researchers investigated the use of $\mathrm{a}_{\mathrm{p}} / \mathrm{f}_{\mathrm{z}}$ ratio significantly lower than one, which is also called "inverse cutting" [9, $10]$.

However, the geometrical features of the cutting insert such as the nose radius $r_{\varepsilon}$, the angle $\kappa_{\mathrm{r}}$ and the rake angle can also play a significant role to the outcome of the process, as they influence the loading conditions on the cutting edge have a considerable impact on surface roughness as well, so that the choice of an insert with appropriate geometry is crucial $[11,12]$. Some of the most frequently used milling inserts are the rectangular, square and round ones [13]. Especially, the round inserts exhibit some peculiarities due to their special form; they do not have a constant entering angle, force and heat distribution are more even and chip thickness varies along the cutting edge $[14,15]$. Despite the fact that, in industrial practice, appropriate cutting inserts are selected based on past experience, only a few research works have been dedicated to the comparison of the performance of different milling insert types. Chen and Hoshi [16] compared rotary round inserts with fixed round inserts and square inserts during milling of $\mathrm{Al}$ composite materials. It was shown that the tool wear of the rotary round insert and surface roughness obtained with it was lower than that of the fixed round insert and even lower than that of the square one.

El- Bestawi et al. [17] stated that round inserts exhibit superior cutting performance compared to square ones, as they have a stronger cutting edge. Gurdal et al. [18] compared the performance of various milling inserts, namely a square, a round and a high feed one, during rough 
milling. They stressed the importance of $\kappa_{\mathrm{r}}$, which regulates the shape and thickness of the chip, as well as the cutting force distribution on the tool. They found that during rough milling, inserts with low $\kappa_{\mathrm{r}}$ angles can improve productivity and reduce chatter and that square inserts exhibited higher tool wear. Antonialli et al. [19] employed tools with very low $\kappa_{\mathrm{r}}$ angles in order to reduce vibrations, as in this case the radial force, acting in a direction in which the tool is less rigid, is considerably reduced and the axial one is increased. Their findings indicated that tools with lower entering angle exhibited diffusion and attrition wear mechanisms, avoiding the cutting edge breakage. Zarkti et al. [13] noted that, in face milling, inserts with entering angle of $45^{\circ}$ are more frequently used, along with tools with $90^{\circ}, 10^{\circ}$ entering angles and round inserts. They also underlined that this angle is the dominant factor affecting the direction of cutting force components as well as chip thickness. Finally, the impact of $\kappa_{\mathrm{r}}$ angle on the $\mathrm{F}_{\mathrm{c}}$ component of force during cutting was determined by Bali $[20,21]$, indicating a clear decrease of $F_{c}$ with increasing $\kappa_{\mathrm{r}}$ as well as a combined effect of $\kappa_{\mathrm{r}}$ along with the nose radius of the cutting tool and depth of cut on $F_{c}$, as can be seen in Fig. 1 (a) and (b).

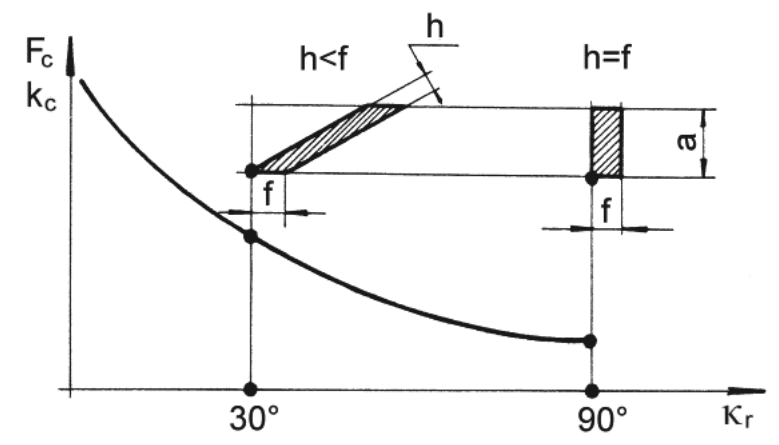

a)

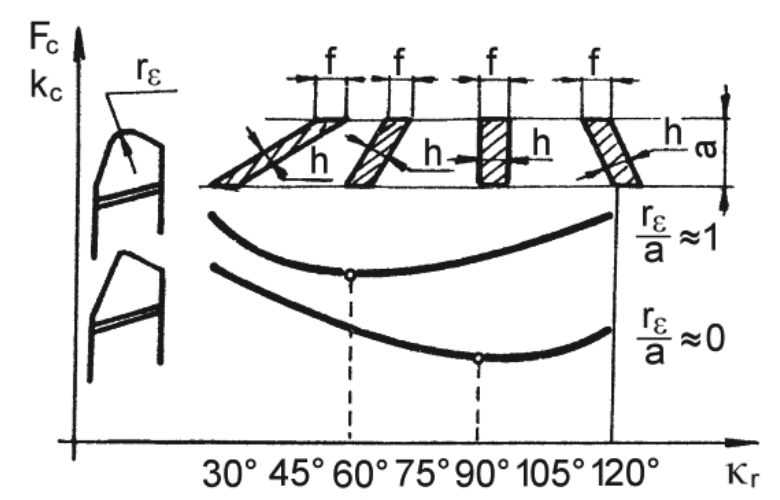

b)

Fig. 1 (a) Variation of $F_{c}$ force component with increasing $\kappa_{r}$ angle, (b) Variation of $F_{c}$ force component in respect to $\kappa_{r}, r_{\varepsilon}$ and $a[20,21]$.

From the brief analysis of the relevant published works, it can be concluded that there is no much research yet conducted regarding the comparison of the performance of various face milling inserts with a wide range of $\kappa_{\mathrm{r}}$ angle values. Thus, in the present paper, experimental work is conducted for the quantitative comparison of three different inserts performance regarding cutting forces and specific cutting forces in order to determine which geometry can be used for efficient material removal with the lowest energy requirements within the studied process parameters range.

\section{Experimental conditions and equipment}

In order to perform the required analysis, face milling experiments with three different cutting inserts were conducted, namely a rectangular, a round and a square insert. The characteristics of the experimental work are summarized in Tab. 1 and briefly described in this section. The face milling experiments were carried out in a Perfect Jet MCV-M8 vertical machining center and the workpiece material in every case was normalised C45 (1.0503) carbon steel with a hardness value of $\mathrm{HB} 180$. The rectangular insert was a Sandvik R215.44-15T308M-WL GC4030 coated carbide insert with $\kappa_{\mathrm{r}}=90^{\circ}, \gamma_{\mathrm{o}}=0^{\circ}, \alpha_{\mathrm{o}}=11^{\circ}$ and $r_{\varepsilon}=0.8 \mathrm{~mm}$, mounted on a Sandvik R252.44-080027$15 \mathrm{M}$ face milling head with a diameter $\left(\mathrm{D}_{\mathrm{t}}\right)$ of $80 \mathrm{~mm}$. The round insert was a Sandvik Coromant RCKT1204M0-PMGC4230 coated carbide insert, mounted on a Sandvik CoroMill R200-068Q27-12L face milling head with a diameter of $68 \mathrm{~mm}$. Moreover, the square insert was a Dijet SEKN 1203 AFTN JC5030 coated carbide insert with $\kappa_{\mathrm{r}}=45^{\circ}, \gamma_{\mathrm{o}}=0^{\circ}, \alpha_{\mathrm{o}}=20^{\circ}$ and $0.85 \times 45^{\circ}$ chamfer, mounted on a Canela 0748.90.063 face milling head with a diameter of $63 \mathrm{~mm}$. Each time only a single insert is mounted on the milling head in order to be able to evaluate clearly the effect of one cutting edge at a time. Moreover, the width of the workpiece was $58 \mathrm{~mm}$ and the cutting length was $50 \mathrm{~mm}$ for every experimental test.

The aim of the present work, illustrated also in Fig. 2, was to determine with which cutting edge geometry the lowest energy requirement for the same removed volume would be attained, within the tested process parameters range. Different cutting inserts and have different $\kappa_{\mathrm{r}}$ and $\alpha_{0}$ angles or different nose radius, which lead to different conditions of imposed load on the cutting edge and workpiece. Thus, the experiments were focused on face milling of steel workpieces with three insert types commonly employed in industrial practice, namely a rectangular, a square and a round milling insert under five different feed per tooth values, in a relatively wide range from 0.1 to $0.8 \mathrm{~mm} /$ tooth in order to conduct a comprehensive study with different material removal rate and consumed power values. In these experiments, depth of cut and cutting speed were kept constant at $0.8 \mathrm{~mm}$ and $200 \mathrm{~m} / \mathrm{min}$, respectively. All experiments were conducted in dry machining conditions and in symmetrical face milling mode. Fig. 2 shows the schematic diagram of the experiments.

The measurement of the three components of cutting forces was conducted by the use of a Kistler 9257A dynamometer, positioned below the workpiece. The three force signals which were obtained for each test, were amplified by three 5011A charge amplifiers and then recorded at a PC via a CompactDAQ-9171 data collector with 
4 channels, by National Instruments. The final processing of force signals was conducted by the use of measurement software in LabView programming language. During the measurements, cutting forces components were recorded with a sampling frequency of $10 \mathrm{kHz}$ in a xyz axes coordinate system, attached to the workpiece; thus the three cutting force components correspond to $\mathrm{Fx}, \mathrm{Fy}, \mathrm{Fz}$ respectively. Nevertheless, the cutting forces components in respect to a coordinate system attached on the tool edge, namely Fc,Ff and Fp are also of particular importance and were also calculated later through conversion of the Fx, Fy,Fz force values, taking into consideration the kinematics of face milling process and geometrical considerations. The conversion between the two different coordinate systems can be conducted by simple trigonometric formulas [6].

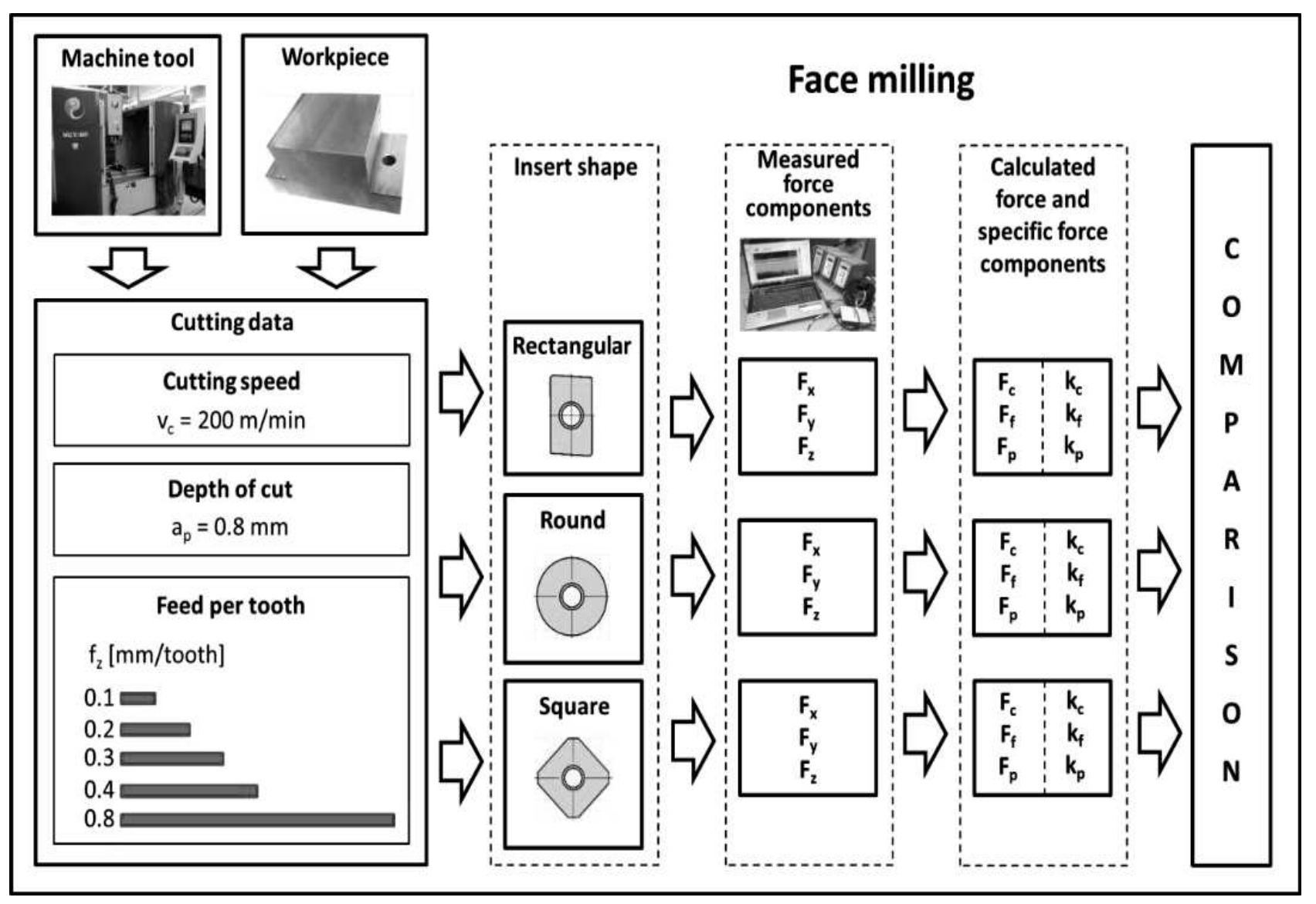

Fig. 2 Schematic diagram of the experiments.

Tab. 1 Details regarding cutting tools and process parameters employed in the experiments.

\begin{tabular}{|c|c|c|c|}
\hline Symbol & & & \\
\hline Insert code & R215.44-15T308M-WL & RCKT1204M0-PM & SEKN 1203 AFTN JC5030 \\
\hline Insert type & Rectangular & Round & Square \\
\hline Details & $\begin{array}{c}\kappa_{\mathrm{r}}=90^{\circ} ; \gamma_{\mathrm{o}}=0^{\circ} ; \alpha_{0}=11^{\circ} ; \\
\mathrm{r}_{\varepsilon}=0.8 \mathrm{~mm}\end{array}$ & $\gamma_{0}=0^{\circ} ; \alpha_{0}=7^{\circ}$ & $\begin{array}{c}\kappa_{\mathrm{r}}=45^{\circ} ; \gamma_{\mathrm{o}}=0^{\circ} ; \alpha_{\mathrm{o}}=20^{\circ} \\
0.85 \mathrm{x} 45^{\circ}\end{array}$ \\
\hline Milling head & $\begin{array}{c}\text { Sandvik R252.44-080027- } \\
15 \mathrm{M}\end{array}$ & $\begin{array}{l}\text { Sandvik CoroMill } \\
\text { R200-068Q27-12L }\end{array}$ & Canela 0748.90.063 \\
\hline Diameter $D_{t}[\mathrm{~mm}]$ & 80 & 68 & 63 \\
\hline Cutting speed [m/min] & \multicolumn{3}{|c|}{200 (constant) } \\
\hline Depth of cut [mm] & \multicolumn{3}{|c|}{0.8 (constant) } \\
\hline Feed per tooth $[\mathrm{mm} /$ tooth] & \multicolumn{3}{|c|}{$0.1,0.2,0.3,0.4,0.8$} \\
\hline
\end{tabular}


Finally, it is important to note that although the force curves relevant to each of the two coordinate systems are generally different, there are specific points where forces of the two systems may coincide [6]. Apart from the forces components, specific force components values are also calculated as the force component values divided by the chip cross section.

\section{Results and discussion}

After the experiments were conducted, the values of the three components of cutting force and specific cutting force were determined and the maximum values of forces in each case for all cutting inserts are presented in Fig. 3, Tab. $2\left(\mathrm{~F}_{\mathrm{x}}, \mathrm{F}_{\mathrm{y}}, \mathrm{F}_{\mathrm{z}}\right)$ and Tab. $3\left(\mathrm{~F}_{\mathrm{c}}, \mathrm{F}_{\mathrm{f}}, \mathrm{F}_{\mathrm{p}}\right)$, in both coordinate systems. Finally, in order to be able to evaluate also the differences between each cutting insert at different feed per tooth values, the percentage of force and specific force values difference between them is calculated and presented in Fig. 4 and Tab. 4, taking the force and specific force component values for the rectangular insert as basis values $(100 \%)$. It is to be noted that the specific force components are denoted with the letter $\mathrm{k}$, with a subscript which is relevant to the force component employed for their calculation.

At first, at it was anticipated, it can be seen that the values of all force components, for all cutting insert types increase with an increase of feed per tooth values, as it is related to more intensive conditions of loading. Accordingly, the values of specific force components decrease, as the increase of feed per tooth leads to an increase of chip cross section.

At first, the variation of forces acting on the workpiece and machine tool (xyz coordinate system) will be discussed. From the results presented in Fig. 3 and 4, regarding $\mathrm{F}_{\mathrm{x}}$ force components, it can be seen that the use of the rectangular milling insert leads to lower cutting force values in almost every case.Moreover, the difference between cutting forces values for cases where the rectangular case was employed and cases where the other two insert types were employed is generally increasing with increased feed per tooth value. Furthermore, the round insert exhibits the highest $F_{x}$ values for almost all cases, followed by the square insert. As for $\mathrm{F}_{\mathrm{y}}$ force component, the same trend as in the case of $F_{x}$ component can be observed, with the lowest force values being observed for the rectangular insert and the highest for the round insert, whereas the square insert exhibits values closer to those of the rectangular insert, especially at low feed per tooth values, with differences in the range of $1-10 \%$. The largest difference between the three cutting inserts is clearly observed regarding the $\mathrm{F}_{\mathrm{z}}$ force component, as the $\mathrm{F}_{z}$ force values for the round insert are even three times larger than those of the other two inserts, with the square cutting insert exhibiting only $13-19 \%$ larger $F_{z}$ values than those of the rectangular one. For the rectangular and the square cutting insert, the force component with the larger values is $\mathrm{F}_{\mathrm{y}}$, especially at higher feed per tooth values, followed by $F_{x}$ and $F_{z}$. However, for the round cutting insert, the $\mathrm{F}_{\mathrm{z}}$ force component exhibits the largest values, especially at low feed per tooth values, followed by $\mathrm{F}_{\mathrm{y}}$ and $\mathrm{F}_{\mathrm{x}}$ force components.

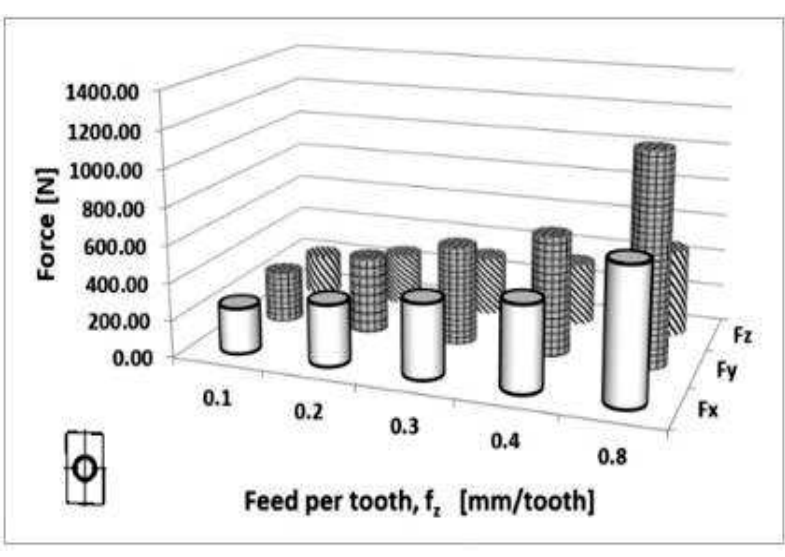

a)

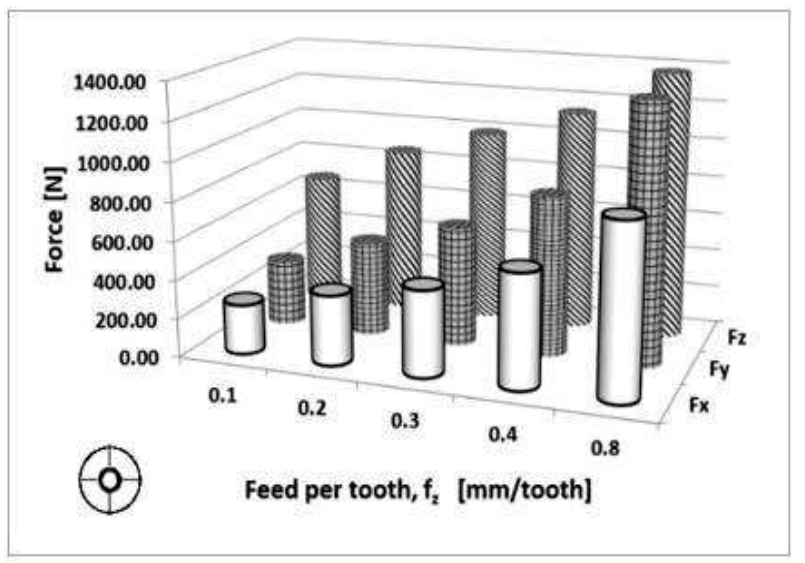

b)

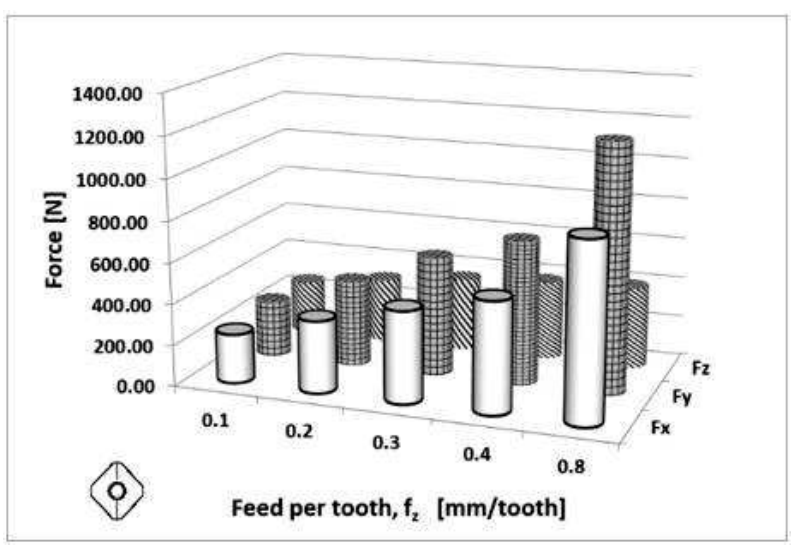

c)

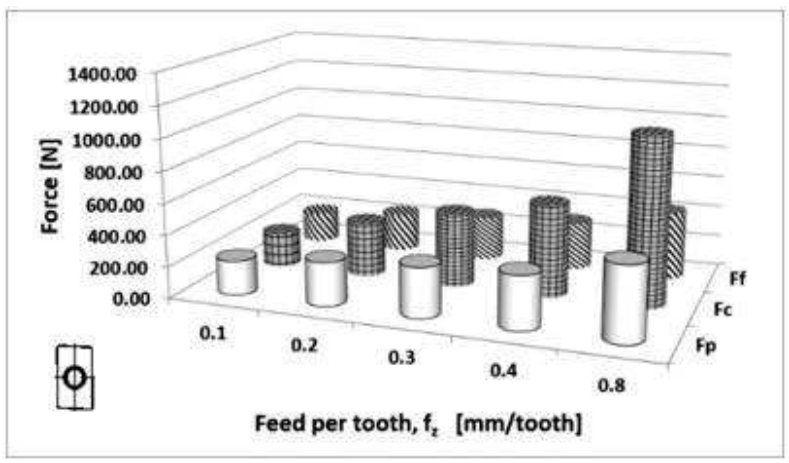

d) 


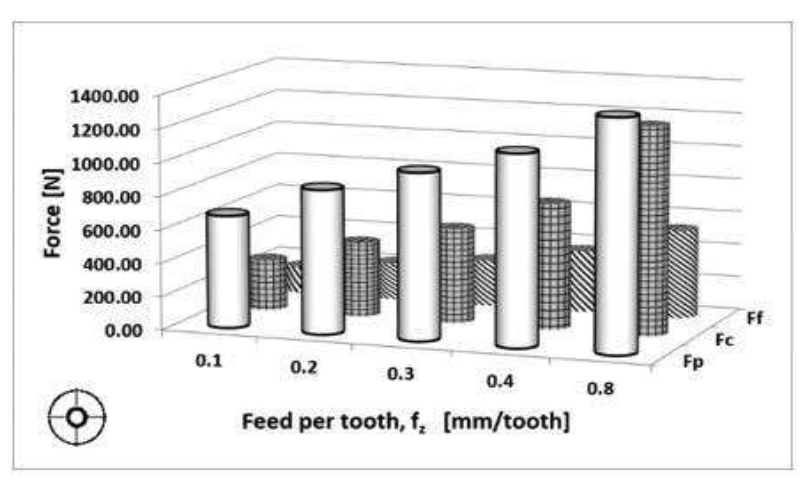

e)

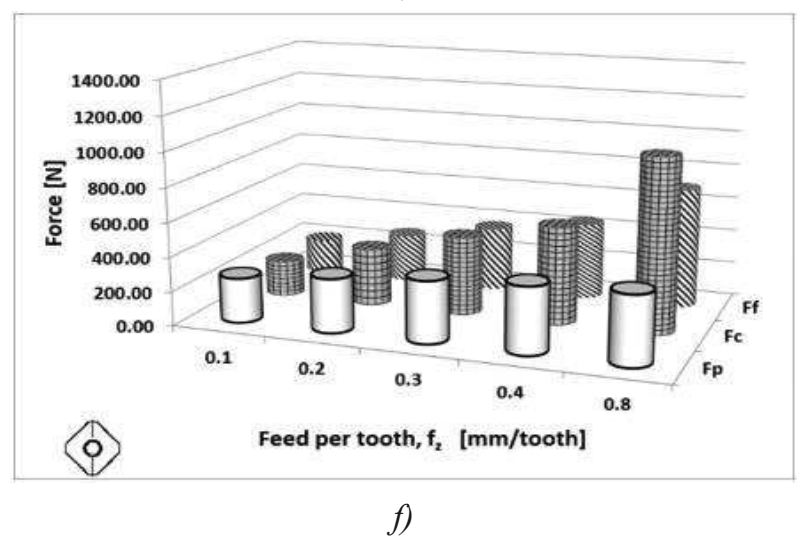

Fig. 3 Maximum values of cutting force components for: (a) rectangular cutting insert in xyz coordinate system,

(b) round cutting insert in xyz coordinate system, (c) square cutting insert in xyz coordinate system, (d) rectangular cutting insert in tool edge coordinate system, (e) round cutting insert in tool edge coordinate system, (f) square insert in tool edge coordinate system.

Tab. 2 Experimental results regarding forces $F_{x}, F_{y}$ and $F_{z}$ for all experiments.

\begin{tabular}{|c|c|c|c|}
\hline \multicolumn{2}{|c|}{$v_{c}=200 \mathrm{~m} / \mathrm{min}$} & \multicolumn{2}{|c|}{$a_{p}=0.8 \mathrm{~mm}$} \\
\hline $\begin{array}{c}\mathrm{f}_{\mathrm{z}} \\
{[\mathrm{mm} / \text { tooth }]}\end{array}$ & $\begin{array}{l}\mathrm{F}_{\mathrm{x}} \\
{[\mathrm{N}]}\end{array}$ & $\begin{array}{c}\mathrm{F}_{\mathrm{y}} \\
{[\mathrm{N}]}\end{array}$ & $\begin{array}{l}\mathrm{F}_{\mathrm{z}} \\
{[\mathrm{N}]}\end{array}$ \\
\hline \multicolumn{4}{|c|}{ Rectangular insert } \\
\hline 0.1 & 246.53 & 272.62 & 219.35 \\
\hline 0.2 & 329.83 & 408.14 & 277.94 \\
\hline 0.3 & 400.42 & 527.69 & 315.38 \\
\hline 0.4 & 458.64 & 640.76 & 337.23 \\
\hline 0.8 & 715.23 & 1132.70 & 469.72 \\
\hline \multicolumn{4}{|l|}{ Round insert } \\
\hline 0.1 & 256.85 & 336.56 & 673.35 \\
\hline 0.2 & 360.62 & 487.30 & 861.82 \\
\hline 0.3 & 443.42 & 615.86 & 997.04 \\
\hline 0.4 & 583.47 & 822.57 & 1141.05 \\
\hline 0.8 & 883.07 & 1335.65 & 1380.69 \\
\hline \multicolumn{4}{|l|}{ Square insert } \\
\hline 0.1 & 240.56 & 275.04 & 260.61 \\
\hline 0.2 & 352.07 & 421.49 & 314.19 \\
\hline 0.3 & 446.42 & 580.98 & 359.69 \\
\hline 0.4 & 538.64 & 701.80 & 386.42 \\
\hline 0.8 & 860.32 & 1202.97 & 401.24 \\
\hline
\end{tabular}

Tab. 3 Experimental results regarding forces $F_{c}, F_{f}$ and $F_{p}$ for all experiments.

\begin{tabular}{|c|c|c|c|}
\hline \multicolumn{2}{|c|}{$\mathrm{vc}_{\mathrm{c}}=200 \mathrm{~m} / \mathrm{min}$} & \multicolumn{2}{|c|}{$a_{p}=0.8 \mathrm{~mm}$} \\
\hline $\mathrm{f}_{\mathrm{z}}$ & $\mathrm{F}_{\mathrm{c}}$ & $\mathrm{F}_{\mathrm{f}}$ & $\mathrm{F}_{\mathrm{p}}$ \\
\hline$[\mathrm{mm} /$ tooth $]$ & {$[\mathrm{N}]$} & {$[\mathrm{N}]$} & {$[\mathrm{N}]$} \\
\hline \multicolumn{4}{|c|}{ Rectangular insert } \\
\hline 0.1 & 219.94 & 196.62 & 219.35 \\
\hline 0.2 & 349.90 & 244.90 & 277.94 \\
\hline 0.3 & 470.17 & 282.96 & 315.38 \\
\hline 0.4 & 586.94 & 304.61 & 337.23 \\
\hline 0.8 & 1066.28 & 432.44 & 469.72 \\
\hline \multicolumn{4}{|l|}{ Round insert } \\
\hline 0.1 & 304.20 & 160.43 & 673.35 \\
\hline 0.2 & 447.50 & 220.75 & 861.82 \\
\hline 0.3 & 566.41 & 273.52 & 997.04 \\
\hline 0.4 & 752.50 & 368.83 & 1141.05 \\
\hline 0.8 & 1246.39 & 530.86 & 1380.69 \\
\hline \multicolumn{4}{|l|}{ Square insert } \\
\hline 0.1 & 208.96 & 200.24 & 260.61 \\
\hline 0.2 & 335.50 & 279.29 & 314.19 \\
\hline 0.3 & 456.21 & 372.74 & 359.69 \\
\hline 0.4 & 567.51 & 449.81 & 386.42 \\
\hline 0.8 & 1009.59 & 703.33 & 401.24 \\
\hline
\end{tabular}

As for the specific cutting forces, it can be observed from Tab. 4, that their variation with different cutting inserts is similar to the variation of their respective force components in respect to different cutting inserts, as well as the trends regarding the percentage difference of specific cutting force values between cases with different cutting inserts, which follows exactly the respective trends of cutting force components in both coordinate systems.

As the cutting force components in a coordinate system attached to the tool edge are related to the chip separation (and subsequently, chip deformation, temperature and stress conditions), the analysis of their value is also of particular interest, especially for the $\mathrm{F}_{\mathrm{c}}$ and $\mathrm{F}_{\mathrm{f}}$ components as the $F_{p}$ component values coincide with those of $F_{z}$. As can be seen in Fig. 3 and 4, regarding the $F_{c}$ component, which acts tangentially on the cutting edge, the highest values are observed in the case of the round insert and the lowest for the square insert; however the difference between the rectangular and the square insert is minimal, in the range of $3-5 \%$.

For the case of the round insert, it is interesting to note that the difference from the rectangular insert is decreasing with increasing feed per tooth value. Regarding the $F_{f}$ component, acting in perpendicular direction to $F_{c}$, the 
lowest values for feed per tooth values lower than 0.4 $\mathrm{mm} /$ tooth are observed for the round insert, whereas the square insert is exhibiting the highest values of $F_{f}$ in any case and its difference from the $\mathrm{F}_{\mathrm{f}}$ values of the rectangular insert is increasing considerably with an increase of $f_{z}$. In the case of rectangular cutting insert, the $\mathrm{F}_{\mathrm{c}}$ force component is by far the largest one compared to $F_{p}$ and $F_{f}$, which constitute the axial and radial components of force, respectively, and have very close values between them. In the case of round cutting insert, the $F_{p}$ force component is the largest, especially for feed per tooth values below 0.8 $\mathrm{mm} /$ tooth, followed by $\mathrm{F}_{\mathrm{c}}$ and $\mathrm{F}_{\mathrm{f}}$. Finally, in the case of square insert, the $F_{c}$ component is the largest in cases above feed per tooth value of $0.1 \mathrm{~mm} /$ tooth, followed by $\mathrm{F}_{\mathrm{f}}$ and $\mathrm{F}_{\mathrm{p}}$; however, for low feed per tooth values, all three components exhibit relatively close values

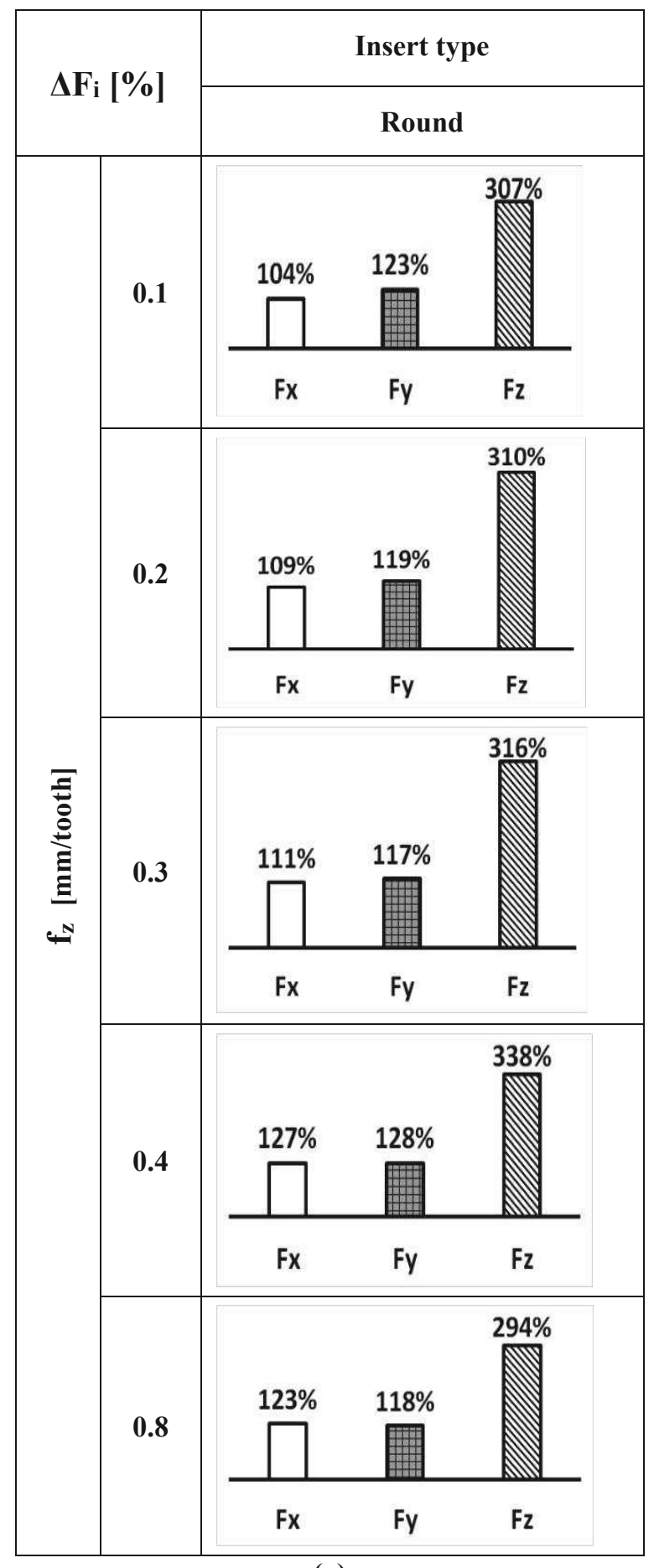

(a)

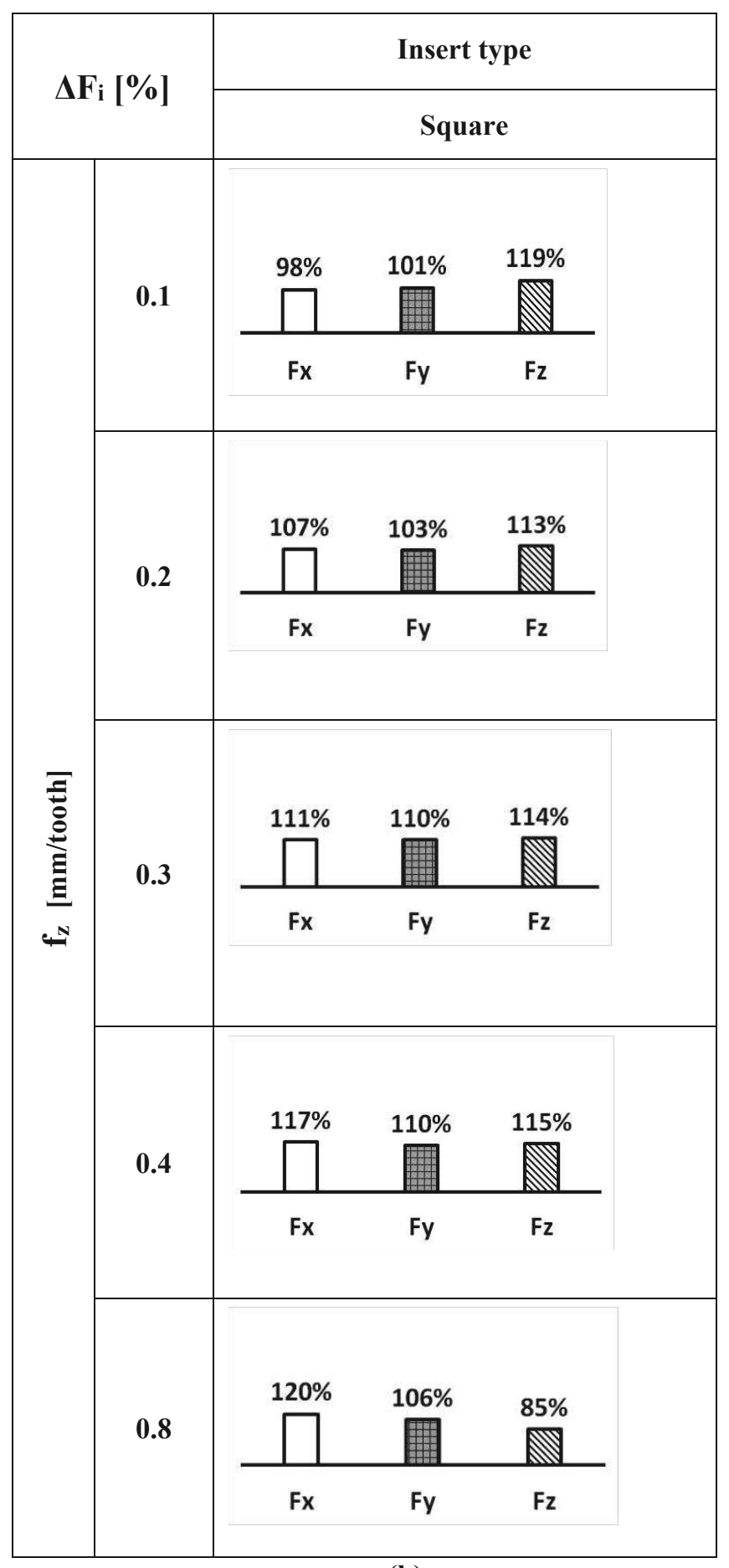

(b) 


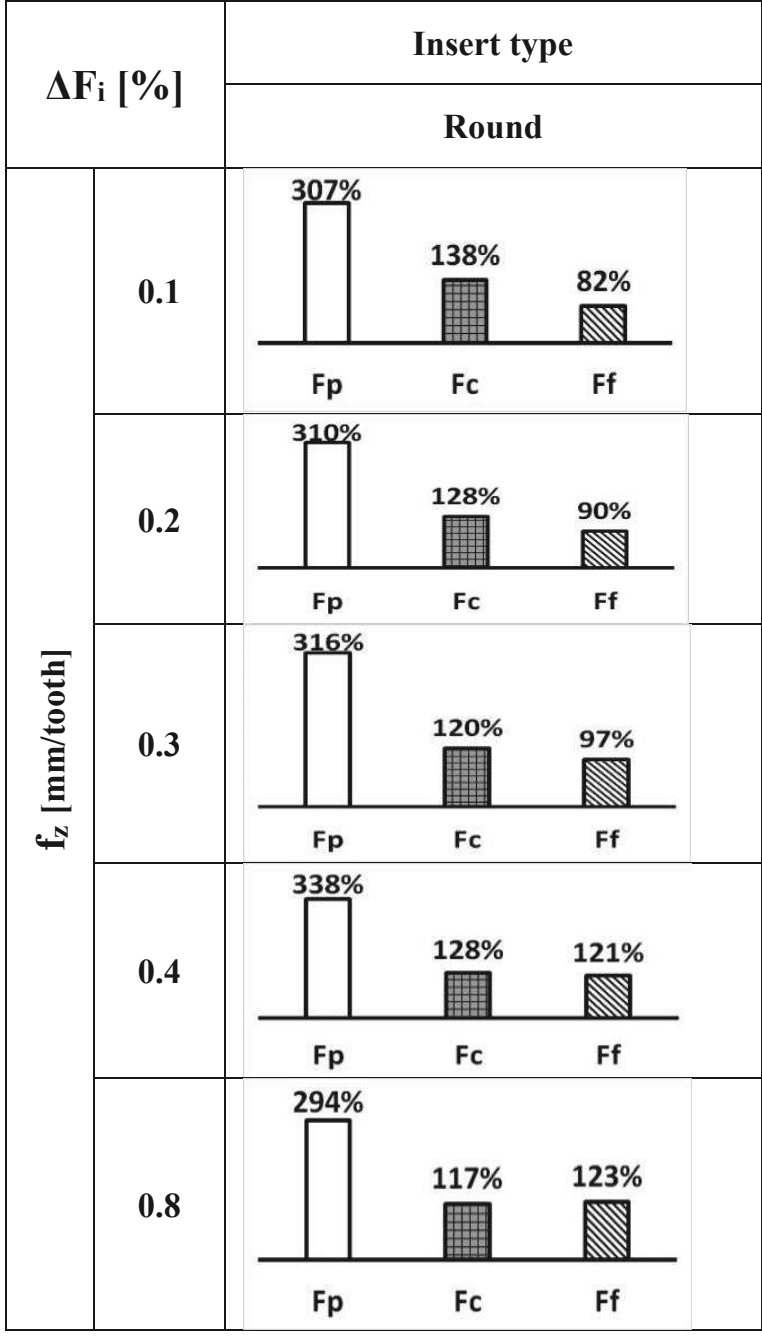

(c)

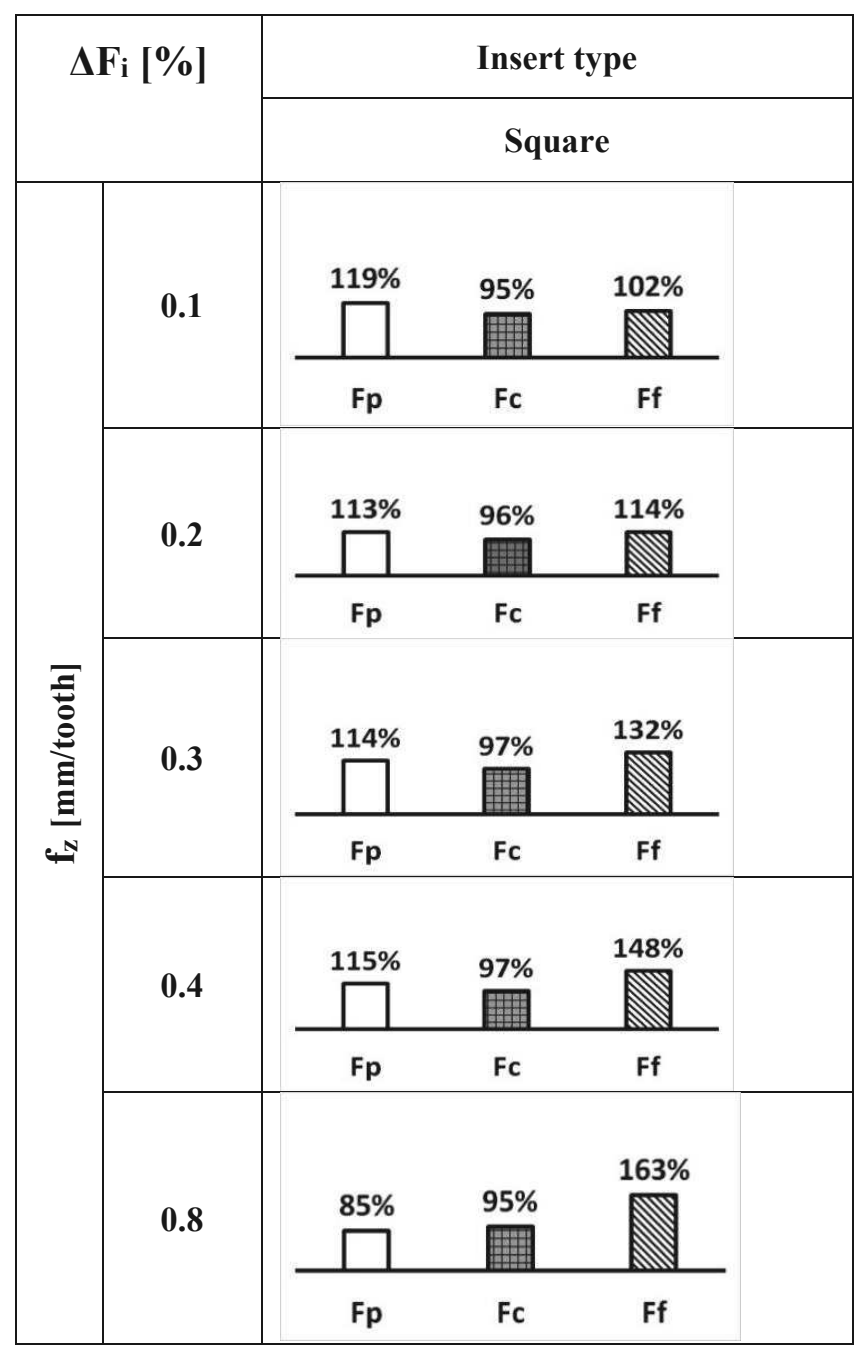

(d)

Fig. 4 Percentage difference of cutting force components: (a) between rectangular and round cutting inserts in xyz coordinate system, (b) between rectangular and square cutting insert in xyz coordinate system, (c) between rectangular and round cutting insert in tool edge coordinate system, (d) between rectangular and square cutting insert in tool edge coordinate system.

Tab. 4 Percentage change of specific cutting forces between cases with different cutting inserts and feed per tooth values in the both coordinate systems $\left(k_{x}, k_{y}, k_{z}, k_{c}, k_{f}\right.$ and $\left.k_{p}\right)$.

\begin{tabular}{|c|c|c|c|c|c|c|c|}
\hline \multicolumn{2}{|c|}{$\mathrm{v}_{\mathrm{c}}=200 \mathrm{~m} / \mathrm{min}$} & \multicolumn{2}{|c|}{$a_{p}=0.8 \mathrm{~mm}$} & \multicolumn{2}{|c|}{$\mathrm{v}_{\mathrm{c}}=200 \mathrm{~m} / \mathrm{min}$} & \multicolumn{2}{|c|}{$a_{p}=0.8 \mathrm{~mm}$} \\
\hline $\begin{array}{c}\mathrm{f}_{\mathrm{z}} \\
{[\mathrm{mm} / \text { tooth }]}\end{array}$ & $\begin{array}{l}\mathrm{k}_{\mathrm{x}} \\
\%\end{array}$ & $\begin{array}{l}\mathrm{k}_{\mathrm{y}} \\
\%\end{array}$ & $\begin{array}{l}\mathrm{k}_{\mathrm{z}} \\
\%\end{array}$ & $\begin{array}{c}\mathrm{f}_{\mathrm{z}} \\
{[\mathrm{mm} / \text { tooth] }}\end{array}$ & $\begin{array}{l}\mathrm{k}_{\mathrm{c}} \\
\%\end{array}$ & $\begin{array}{l}\mathrm{k}_{\mathrm{f}} \\
\%\end{array}$ & $\begin{array}{l}\mathrm{k}_{\mathrm{p}} \\
\%\end{array}$ \\
\hline \multicolumn{4}{|l|}{ Rectangular insert } & \multicolumn{4}{|c|}{ Rectangular insert } \\
\hline $0.1-0.8$ & 100 & 100 & 100 & $0.1-0.8$ & 100 & 100 & 100 \\
\hline \multicolumn{4}{|l|}{ Round insert } & \multicolumn{4}{|c|}{ Round insert } \\
\hline 0.1 & 104 & 123 & 307 & 0.1 & 138 & 82 & 307 \\
\hline 0.2 & 109 & 119 & 310 & 0.2 & 128 & 90 & 310 \\
\hline 0.3 & 111 & 117 & 316 & 0.3 & 120 & 97 & 316 \\
\hline 0.4 & 127 & 128 & 338 & 0.4 & 128 & 121 & 338 \\
\hline 0.8 & 123 & 118 & 294 & 0.8 & 117 & 123 & 294 \\
\hline \multicolumn{4}{|l|}{ Square insert } & \multicolumn{4}{|c|}{ Square insert } \\
\hline 0.1 & 98 & 101 & 119 & 0.1 & 95 & 102 & 119 \\
\hline 0.2 & 107 & 103 & 113 & 0.2 & 96 & 114 & 113 \\
\hline 0.3 & 111 & 110 & 114 & 0.3 & 97 & 132 & 114 \\
\hline 0.4 & 117 & 110 & 115 & 0.4 & 97 & 148 & 115 \\
\hline 0.8 & 120 & 106 & 85 & 0.8 & 95 & 163 & 85 \\
\hline
\end{tabular}




\section{Conclusions}

In this paper the effect of different cutting insert geometrical characteristics on cutting force and specific cutting force components values for cases of face milling with a single cutting insert was examined in order to determine the insert with the appropriate cutting edge geometry leading to the lowest energy consumption for the same material removed volumes. For each cutting insert, experiments with five different feed per tooth values, ranging from 0.1 to $0.8 \mathrm{~mm} /$ tooth were carried out and the variation of maximum values of cutting force and specific cutting force components was analysed in respect to different experimental conditions.

Regarding the cutting force components acting on the workpiece, it was found that almost in every case, the rectangular cutting insert exhibited the lowest force values, with the square exhibiting slightly larger force values and the round insert exhibiting the highest force values. Especially regarding the $\mathrm{F}_{\mathrm{z}}$ component, forces obtained in cases where the round insert was used, exceeded the forces obtained by the other two inserts even by three times.

Regarding the cutting force components in a coordinate system attached to the tool edge and related to the chip separation, for the $F_{c}$ component, the round tool exhibited the highest force values, followed by the rectangular and the square tools whose values were close. For the $\mathrm{F}_{\mathrm{f}}$ component, the square insert exhibited the highest force values followed by the other two ones. In general, the rectangular and square inserts exhibited considerably higher $F_{c}$ force value than $F_{p}$ and $F_{f}$ ones, whereas for the round insert, $F_{p}$ were the highest, followed by $F_{c}$ and $F_{f}$ values.

Moreover, the specific cutting force components, although their values decrease with increase of feed per tooth values due to the increase of chip cross section, exhibited similar trends with their respective force components regarding their variation in respect to the cutting insert geometries. Furthermore, same percentage differences as in the case of cutting forces were observed between the specific cutting force values obtained with the square and round inserts and the rectangular one.

In conclusion, experimental results have shown that, based on the measured cutting force components and in order to consume the minimum power, the inserts can be recommended for use in the following order: rectangular, square, round.

\section{Acknowledgement}

The authors greatly appreciate the support of the National Research,Development and Innovation Office NKFIH (No. of Agreement: K 116876). The describedstudy was carried out as part of the EFOP-3.6.1-1600011 "Younger and Renewing University - Innovative Knowledge City - institutional development of the University of Miskolc aiming atintelligent specialization" project implemented in the framework of the Szechenyi 2020 program.Both supports are gratefully acknowledged.

\section{References}

[1] ILLÉS, B., TAMÁS, P., DOBOS, P., SKAPINYECZ, R. (2017). New challenges for quality assurance of manufacturing processes in industry 4.0. In: Solid State Phenomena, Vol. 261, pp. $481-486$.

[2] MUÑOZ-ESCALONA, P., MAROPOULOS, P.G. (2015). A geometrical model for surface roughness prediction when face milling Al 7075T7351 with square insert tools. In: Journal of Manufacturing Systems, Vol. 36, pp. 216-223.

[3] SURESH KUMAR REDDY, N., VENKATESWARA RAO, P. (2005). Selection of optimum tool geometry and cutting conditions using a surface roughness prediction model for end milling. In: International Journal of Advanced Manufacturing Technology, Vol. 26, No. 11-12, pp. 1202-1210.

[4] BHARATHI RAJA, S., BASKAR, N. (2012). Application of particle swarm optimization technique for achieving desired milled surface roughness in minimum machining time. In: Expert Systems with Applications, Vol. 39, No. 5, pp. 5982-5989.

[5] ABD ALI, R., MIA, M., KHAN, A.M., CHEN, W., GUPTA, M.K., PRUNCU, C.I. (2019). Multiresponse optimization of face milling performance considering tool path strategies in machining of Al-2024. In: Materials, Vol. 12, No. 7, 1013.

[6] KUNDRÁK, J., MARKOPOULOS, A.P., MAKKAI, T., DESZPOTH, I., NAGY, A. (2018). Analysis of the effect of feed on chip size ratio and cutting forces in face milling for various cutting speeds. In: Manufacturing Technology, Vol. 18, No. 3, pp. 431-438.

[7] KARKALOS, N.E., MAKKAI, T., MARKOPOULOS, A.P., KUNDRÁK, J. (2019). Influence of depth of cut and cutting speed on cutting forces in face milling under constant chip cross-section conditions. In: Cutting \& Tools in Technological System, Vol. 90, pp. 10-16.

[8] KUNDRÁK, J., GYÁNI, K., FELHÖ, C., DESZPOTH, I. (2017). The effect of the shape of chip cross section on cutting force and roughness when increasing feed in face milling. In: Manufacturing Technology, Vol. 17, No. 3, pp. 335-342.

[9] KARPUSCHEWSKI, B, BATT, S. (2007). Improvement of Dynamic Properties in Milling by Integrated Stepped Cutting. In: CIRP Annals-Manufacturing Technology, Vol. 56, No. 1, pp. 85-88.

[10] KARPUSCHEWSKI, B., KUNDRÁK, J., EMMER, T., BORYSENKO, D. (2017). A new strategy in face milling - inverse cutting technology. In: Solid State Phenomena, Vol. 261, pp. 331-338.

[11] FELHÖ, C., KUNDRÁK, J. (2014). Comparison of theoretical and real surface roughness in face 
milling with octagonal and circular inserts. In: Key Engineering Materials, Vol. 581, pp. 360-365.

[12] KUNDRÁK, J., FELHÖ, C. (2016). 3D roughness parameters of surfaces face milled by special tools. In: Manufacturing Technology, Vol. 16, No. 3, pp. 532-538.

[13] ZARKTI, H., El MESBAHI, A., RECHIA, A., JAIDER, O. (2015). Towards an automatic-optimized tool selection for milling process, based on data from Sandvik Coromant. In: Xème Conférence Internationale: Conception et Production Intégrées, Tanger, Morocco.

[14] ANTONIALLI, A.I.S., DINIZ, A. E., PEDERIVA, R. (2010). Vibration analysis of cutting force in titanium alloy milling. In: International Journal of Machine Tools and Manufacture, Vol. 50, No. 1, pp. 65-74.

[15] GHORBANI, H., MOETAKEF-IMANI, B. (2016). Specific cutting force and cutting condition interaction modeling for round insert face milling operation. In: International Journal of Advanced Manufacturing Technology, Vol. 84, No. 5-8, pp. 1705-1715.

[16] CHEN, P., HOSHI, T. (1992). High-performance machining of $\mathrm{SiC}$ whisker-reinforced aluminum composite by self propelled rotary tools. In: CIRP Annals, Vol. 41, No. 1, pp. 59-62.

[17] El BESTAWI, M.A., El WARDANY, T.I., YAN, D., TAN, M. (1993). Performance of whisker-reinforced ceramic tools in milling nickel-based superalloy. In: CIRP Annals, Vol. 42, No. 1, pp. 99102.

[18] GURDAL, O., WRIGHT, A., CARPENTER,C., BLACKMORE, M. (2018). Investigation of the performance of different face milling inserts to improve rough milling of SA508 Grade 3 forgings. In: Proceedings of the ASME 2018 Pressure Vessels and Piping Conference PVP 2018, Prague, Czech Republic.

[19] ANTONIALLI, A.I.S., DINIZ, A.E., PEDERIVA, R. (2010). Vibration analysis of cutting force in titanium alloy milling. In: International Journal of Machine Tools and Manufacture, Vol. 50, pp.6574.

[20] BALI, J. (1980).Forgácsolás. Tankönyvkiadó, Budapest.

[21] BALI, J. (1985).Forgácsolás. Tankönyvkiadó, Budapest. 